\title{
DNA Folding
}

National Cancer Institute

\section{Source}

National Cancer Institute. DNA Folding. NCI Thesaurus. Code C19359.

Energetics and biophysical mechanisms of DNA higher order structure 